\title{
ANÁLISE DE UM LIVRO DIDÁTICO DE LÍNGUA PORTUGUESA: ENSINO TRADICIONAL DE GRAMÁTICA VERSUS GÊNEROS DISCURSIVOS E ANÁLISE LINGUISTIICA
}

\author{
ANALYSIS OF A PORTUGUESE TEXTBOOK: TRADITIONAL TEACHING VERSUS \\ DISCOURSE GENRES AND LINGUISTIC ANALYSIS
}

\author{
Marco André Franco de Araújo* \\ Éderson Saraiva** \\ Sinval Martins de Sousa Filho ${ }^{* \star *}$
}

\begin{abstract}
RESUMO
Neste artigo, refletimos sobre a influência do livro didático (LD) na condução de atividades tradicionais de gramática na sala de aula e sobre a possibilidade do LD potencializar atividades relacionadas aos gêneros discursivos e ao eixo pedagógico análise linguística nas aulas de língua portuguesa. O objetivo geral do estudo é descrever e analisar como as atividades propostas no LD são dispostas e como podem estar relacionadas com alguns pressupostos das teorias linguísticas contemporâneas. Dessa forma, fundamentamos nosso trabalho apresentando as concepções de linguagem (BAKHTIN, 2009; CHOMSKY, 1957, entre outros), as teorias dos gêneros discursivos (BAKHTIN, 2011; FARACO, 2009) como, também, do ensino de análise linguística (FRANCHI, 2006; GERALDI, 1997, 2016). Pontuamos, ainda, alguns aspectos do uso do livro didático em sala de aula (CORACINI, 1999; LAJOLO, 1996) e, por fim, apresentamos o livro Projeto Teláris, utilizado neste trabalho. Para tanto, tendo como principal recurso o livro didático, realizamos uma pesquisa documental de cunho qualitativo (GIL, 2010; SILVA; MENEZES, 2005). Os dados coletados e analisados sugerem um mascaramento das atividades tradicionais, as quais são nomeadas com termos provenientes de teorias linguísticas contemporâneas, mas, em sua maioria, recaem no ensino explícito de gramática e, assim, se afastam das teorias dos gêneros do discurso e da análise linguística e direcionam o ensino do professor para um trabalho engessado e gramatiqueiro. Palavras-chave: livro didático; gêneros do discurso; análise linguística.
\end{abstract}

\section{ABSTRACT}

In this paper, we discuss the influence of textbooks on traditional grammar activities in classrooms, and the possibilities of using them to potentialize activities based on the perspective of the discourse genres on the teaching of linguistic analysis in Portuguese language classes. We mainly aim at describing and analyzing how activities proposed by the textbooks are arranged and how they are related to contemporary theories and assumptions. Thus, we based our work on the concepts of language (BAKHTIN, 2009; CHOMSKY, 1957; 2006, among others), the theories of discursive genres (BAKHTIN, 2011; FARACO, 2009) and the linguistic analysis teaching (FRANCHI, 2006; GERALDI, 1997). We also discuss some aspects of the use of textbook in classroom (CORACINI, 1999; LAJOLO, 1996) and, finally, we present the textbook Project Teláris, used in this study. Therefore, we conducted a qualitative documentary research (GIL, 2010; SILVA; MENEZES, 2005). The data collected and analyzed suggest a masking of traditional activities, which are named with terms from contemporary linguistic theories, but, for the most part, fall into the explicit teaching of grammar and thus move away from the theories of discourse genres and linguistic analysis and direct teaching to a plastered and grammatical work.

Keywords: textbook; discourse genres; linguistic analysis.

\section{INTRODUÇÃO}

O ensino tradicional de gramática nas escolas públicas tem sido, ao longo de décadas, norteado pelo livro didático (LD), o qual, na maioria das vezes, é utilizado pelos professores como o único material didático que é disponível para o docente (SOUSA FILHO, 2009). Tendo em vista essa presença, podemos dizer que a interferência do LD no processo de ensino e aprendizagem de língua portuguesa é inegável e que podemos (re)pensar as teorias que embasam tais dispositivos pedagógicos, visto que, mediante o uso do LD, o professor pode fazer com que o ensino de língua portuguesa seja efetuado a partir do ensino tradicional de gramática ou pode também incluir novos instrumentos de ensino, como os gêneros discursivos e as atividades de análise linguística.

\footnotetext{
* Doutorando em Letras e Linguística pela Universidade Federal de Goiás (UFG), Goiânia, GO, Brasil. professormarcoandre@gmail.com Orcid: https://orcid.org/0000-0001-6294-8196

** Mestrando em Letras e Linguística pela Universidade Federal de Goiás. (UFG), Goiânia, GO, Brasil. 1601.saraiva@gmail.com Orcid: https://orcid.org/0000-0002-2118-8044

*** Universidade Federal de Goiás. (UFG), Goiânia, GO, Brasil.sinvalfilho7@gmail.com Orcid: https://orcid.org/0000-0003-2205-5865
} 
Sabemos que um livro didático é elaborado a partir de uma base teórica, sobretudo mediante teorias correntes e vistas como possíveis de serem aplicadas ao ensino (SOUSA FILHO, 2009; GERALDI, 2015). Desta forma, dos conjuntos de LD de língua portuguesa feitos a partir da década de 1990, uma característica é marcante na maioria deles: a presença dos mais variados gêneros discursivos/textuais, os quais, segundo Cerutti-Rizzati (2010) e Geraldi (2015), podem possibilitar o ensino da língua em suas nuances de uso significativo e por meio da interação. Porém, nas escolas brasileiras, o uso dos gêneros discursivos é reduzido a meio instrumental para a realização de exercícios puramente gramaticais (SOUSA FILHO, 2017).

Neste artigo, a partir da perspectiva da teoria dos gêneros discursivos e com foco no ensino de análise linguística, apresentamos análises de algumas atividades do livro Projeto Teláris - Lingua Portuguesa, publicado em 2015 pela editora Ática, indicado para o $6^{\circ}$ ano do Ensino Fundamental, elaborado pelas professoras Ana Maria Trinconi Borgatto, Terezinha Costa Hashimoto Bertin e Vera Lúcia de Carvalho Marchezi. De acordo com Rabelo (2015), o referido livro é visto como um material de ponta e tem sido um dos mais adotados nas várias escolas da educação básica brasileira desde 2012. Ainda assim, do nosso ponto de vista, faltam muitas adequações ao LD para que, a partir dele, o trabalho com gêneros discursivos e com o eixo didático análise linguística, mediante a concepção de linguagem como interação, possa ser efetivado.

Por intermédio de nossas análises, buscamos criticar os reducionismos das atividades voltadas para o trabalho com gêneros discursivos e nomenclaturas gramaticais e buscamos demonstrar como tais atividades podem ser redimensionadas para que a análise linguística e o uso dos gêneros discursivos como (mega)instrumentos de ensino possam alcançar o chão da escola.

A seguir, apresentamos a fundamentação teórica por nós adotada neste estudo, enfatizando a concepção interacionista de linguagem e procurando discutir de que forma, por meio da linguagem, o aluno pode se constituir como sujeito. Refletimos, também, sobre aspectos da teoria dos gêneros discursivos e da análise linguística nas aulas de Português. Na sequência, apresentamos a metodologia adotada para o estudo e, em seguida, propomos uma discussão das atividades elaboradas pelas autoras do livro didático. Por fim, tecemos nossas considerações finais.

\section{A CONCEPÇÃO INTERACIONISTA DA LINGUAGEM E A CONSTITUIÇÃO DOS SUJEITOS}

Ancorados em Bakhtin (2009), delineamos o que se entende por concepção interacionista de linguagem e qual é a concepção de sujeito emergente dos estudos bakhtianianos.

Para Bakhtin (2009), a linguagem não é um mero conjunto de regras e estruturas, mas um sistema com características funcionais e psicológicas que funciona como atividade constituída e constitutiva ao mesmo tempo em que é usada por interlocutores históricos. Nas palavras do Bakhtin (2009, p. 128), "a língua vive e evolui historicamente na comunicação verbal concreta, não no sistema linguístico abstrato das formas da língua nem no psiquismo individual dos falantes". Por meio da linguagem, o indivíduo interage com seus semelhantes e na interação se comunica, se expressa e se faz interlocutor.

Sendo assim, Bakhtin (2009) considera a linguagem como essencialmente social, ideológica e dialógica, como um fato social repleto de posicionamentos axiológicos. Fundamentada no fenômeno da interação verbal, a linguagem se realiza por meio de enunciações, as quais são realizadas por enunciados orais e escritos. O conjunto desses enunciados formam os gêneros discursivos, que funcionam como correias de transmissão que unem história da sociedade e história da(s) língua(s). Conforme afirma Bakhtin (2011), nenhum fenômeno linguístico entra no sistema de uma língua sem antes ter passado pelo crivo do uso nos enunciados/gêneros discursivos.

Nesse sentido, como esclarecem Araújo, Sousa Filho e Lima (2018, p. 275) a concepção interacionista da linguagem, diferentemente de outras concepções de linguagem, "compreende a historicidade dos sujeitos e não descarta a intencionalidade e os condicionantes pragmáticos subjacentes às produções comunicativas". Já a perspectiva behaviorista conceitua a linguagem como um processo de formação de hábitos, entendendo que o indivíduo adquire a língua por meio de repetições até que esse processo seja internalizado, conforme postulam Bloomfield (1933) e Skinner (1957), entre outros. Em contrapartida, o inatismo, discutido por Chomsky (1957), considera a linguagem como uma capacidade inata dos indivíduos, sendo, pois, adquirida por meio da exposição à língua. Assim, percebe-se que há no behaviorismo a centralização do objeto enquanto que no inatismo centraliza-se o sujeito, visto que ambas as vertentes tratam tanto o sujeito como a língua/gem (objeto) como imanentes. 
Não desconsideramos as concepções de Skinner e Chomsky, todavia, o foco do nosso trabalho é a perspectiva interacionista de linguagem, como já citamos. Nesse sentido, destacamos que os estudos de Bakhtin $(2009,2011)$ centram-se em participantes reais (falante, ouvinte, escritor, leitor) da comunicação discursiva. Trata da linguagem viva que, assim como os seus usuários, exige atitude responsiva, isto é, demanda respostas. Tais repostas podem ser em forma de concordância, objeção, execução, mas também podem se dar de forma silenciosa. Dessa forma, todo falante é também respondente.

Tendo em vista essa noção de linguagem interativa, de atividade, aproximamos postulados teóricos de Bakhtin e Vygotsky, enfatizando que ambos são "profundamente interessados no contexto social do discurso, explorando a linguagem em uso" (MARCHENKOVA, 2005, p. 174, grifo no original). Para Marchenkova (2005), o interesse de Bakhtin no diálogo corresponde ao interesse de Vygotsky na linguagem, sendo esta um processo social que, por sua vez, é mediado entre os sujeitos através da interação entre eles.

A partir de uma concepção ativa, os estudos de Bakhtin (2009 e 2011) tomam linguagem, objeto e sujeito envoltos em interações socioculturais e históricas. De acordo com Geraldi (2016), não há especificamente uma teoria de Bakhtin sobre o sujeito e, por isso, o que se pode fazer para entender essa categoria é identificar indícios ou pistas da noção bakhtiniana de constituição da consciência enquanto internalização da palavra alheia. Para Geraldi (2016), tais pistas nos indicam ser o sujeito discursivo o lugar de constante dispersão e aglutinação de vozes, estas ideologicamente marcadas e socialmente situadas. Ou seja, o sujeito, assim como o diálogo, se faz na fronteira com o outro em relações dinâmicas e não estáticas ou lineares. Assim, das noções bakhtinianas, conforme Geraldi (2016), é possível vislumbrar que o sujeito está sempre se fazendo e, por isso, nunca é igual a si mesmo e é sempre inconcluso, ou seja, é um sujeito histórico de uma incompletude fundante.

Ainda segundo Geraldi (2016), o sujeito bakhtiniano encontra-se numa arena ou meio social em que o diálogo harmonioso ou conflituoso direciona as constituições da linguagem e do sujeito. Dessa maneira, encontramos aí um sujeito conflitante que luta para se impor e se situar em meio às ações da linguagem. Essas ações dão a esses atores sociais os elementos para uma existência individual e social. Para Geraldi (2016), há três tipos de ações do sujeito com a linguagem, a saber: i) ações que fazem com a linguagem, ii) ações que fazem sobre a linguagem e iii) ações da linguagem.

Assim, por meio da linguagem, a constituição do sujeito acontece, uma vez que o diálogo faz parte dos processos de interação entre os indivíduos. Conforme esclarece Faraco (2009, p. 68), o diálogo se constitui em uma "significação social marcadamente positiva, que remete a 'solução de conflitos', a 'entendimento', a 'geração de consenso'". Dessa forma, os sujeitos são únicos e singulares, porém, não terminados e intermináveis, conforme sugerem Pires e Sobral (2013), os quais esclarecem que a subjetividade do indivíduo "vai se formando continuamente em novas relações com os outros e em nossas relações com os outros". (PIRES; SOBRAL, 2013, p. 210).

Dessa forma, de acordo com Bakhtin (2011), por meio da interação entre os sujeitos, a linguagem é permeada pela diversidade de gêneros discursivos existentes e, assim, leva o indivíduo a se constituir como sujeito na sociedade em que está inserido e nas práticas letradas sociais, ao passo que, segundo esclarece Faraco (2009, p. 57), a "língua é também e principalmente um conjunto indefinido de vozes sociais".

E nesse conjunto indefinido de vozes, surge também um conjunto infinito de gêneros discursivos, discutido na próxima seção.

\subsection{Os gêneros discursivos na interação social}

De acordo com Marcuschi (2008), os estudos sobre gêneros do discurso não são novos. Desde a antiguidade, a expressão gênero esteve presente na tradição dos estudos ocidentais, especialmente nas sistematizações dos gêneros literários, as quais foram feitas a partir de Platão, Aristóteles, Horácio e Quintiliano. Para Marcuschi (2008), os estudos dos gêneros não estão relacionados apenas aos da literatura, mas se referem às categorias do discurso falado ou escrito, tanto os literários quanto os não literários. Ainda, no cerne da teoria dos gêneros, há três elementos essenciais, a saber: a) aquele que fala, b) aquilo sobre o que se fala e c) aquele a quem se fala.

Os gêneros dos discursos, vistos a partir da ótica bakhtiniana, são maneiras de ações e de funções sociais, isto é, são formas de interações sociais. Os gêneros discursivos estão em movimento constante, por isso, Bakhtin (2009) afirma que eles são relativamente estáveis, estando em consonância com as mudanças desenvolvidas nos campos/ esferas de atividades humanas/sociais. 
Dessa forma, podemos afirmar que os gêneros do discurso permeiam a linguagem e estão presentes em sua multiplicidade em todos os lugares e em diversos suportes, principalmente nos livros didáticos. Como acentuamos anteriormente, os gêneros são considerados fundamentais no processo de comunicação entre as pessoas. Nessa perspectiva, compreendemos, então, que os indivíduos têm contato a todo momento com os gêneros discursivos e se comunicam por meio deles (BAKHTIN, 2011; FARACO, 2009; MACHADO, 2013).

Assim, todos os campos das atividades do homem estão correlacionados ao uso da linguagem e, nesse sentido, esse uso acontece através dos enunciados, sejam eles orais ou escritos. Para Bakhtin (2011, p. 262, grifo do autor), "cada enunciado é particular e individual, mas cada campo da utilização da língua elabora seus tipos relativamente estáveis de enunciados, os quais denominamos gêneros do discurso".

Bakhtin (2011) ainda sugere a divisão dos gêneros discursivos em dois grandes grupos, os gêneros primários (oriundos de aspectos mais simples de uso da linguagem) e os gêneros secundários (oriundos de situações culturalmente mais complexas). Ainda, conforme esclarece o autor, ambos possuem a mesma essência, ou seja, são produzidos em situações de comunicação entre os falantes. Porém, o que irá os diferenciar serão suas condições de produção.

Observando esses apontamentos, compreende-se que o indivíduo, ao estar inserido em práticas de determinada atividade, precisa também ter domínio dos gêneros, os quais, por sua vez, são característicos de cada esfera dessas atividades. No entanto, conforme considera Faraco (2009, p. 131),

são muitas as pessoas que, mesmo dominando muito bem a língua, sentem-se logo desamparadas em certas esferas da comunicação verbal, precisamente pelo fato de não dominarem, na prática, as formas do gênero de cada esfera. Uma pessoa que domina os modos de dizer numa esfera da comunicação cultural (sabe, por exemplo, dar uma aula, travar uma discussão científica, elaborar um tratado filosófico, escrever um poema), pode se sentir pouco à vontade em outra: cala-se ou então intervém de maneira muito desajeitada numa conversa social ou numa assembleia de sindicato.

Assim, como observamos, as pessoas (alunos) podem estar inseridas em determinada esfera social em que o uso da linguagem não lhe seja favorável, não por falta de dominar as estruturas da sua língua, mas, sim, por falta de conhecimento de um rol gigantesco de gêneros que permeiam o uso da língua portuguesa.

Contudo, segundo Cerutti-Rizzatti (2010), não é produtivo que os LD oferecidos aos professores e alunos da educação básica busquem "abraçar" todos esses gêneros, pois o máximo que pode acontecer - e acontece - é que as aulas virem laboratórios de taxonomia de gêneros, tarefa que não se difere muito das classificações de nomenclaturas de itens gramaticais. Segundo Cerutti-Rizzatti (2010) e Geraldi (2016), a escola deve escolher os gêneros mais usados e centrar-se neles durante as aulas de língua portuguesa. Agindo assim, pode ser que a turma (professores e alunos) possa ter mais aproveitamento dos gêneros e, com isso, ter uma melhor formação em leitura, escrita, fala e escuta.

Sobre o livro didático, na próxima seção, apontamos breves considerações e, ainda, apresentamos o material escolhido para análise neste artigo.

\subsection{0 livro didático}

O livro didático assume um papel importante em sala de aula, ou seja, ele é um dos instrumentos de mediação no processo de ensino e auxilia o professor em sua prática. No entanto, em muitos contextos de ensino o livro didático é a principal ferramenta no processo de ensino e aprendizagem e, dessa forma, o ensino passa a ser enfadonho e engessado (CORACINI, 1999; LAJOLO, 1996; MELO, 1999; SOUSA FILHO, 2009).

Em contrapartida, o livro didático pode e deve ser um aliado do professor, porém, o docente deve fazer o uso pertinente desse recurso, a fim de tratar dos assuntos abordados neles de forma significativa para o seu aluno.

O livro didático selecionado como ponto de partida deste estudo é o Projeto Teláris - Língua Portuguesa, do $6^{\circ}$ ano do Ensino Fundamental, elaborado pelas professoras Ana Maria Trinconi Borgatto, Terezinha Costa Hashimoto Bertin e Vera Lúcia de Carvalho Marchezi.

Resumidamente, podemos dizer que a premissa de ensino do referido livro didático gira em torno da teoria dos gêneros que, segundo as autoras, "são elementos desencadeadores de estudo e de reflexão sobre diversas práticas de linguagem: leitura, escuta, produção de textos oral e escrita, relações intertextuais, reflexão e análise linguística" (BORGATTO; BERTIN; MARCHEZI, 2015, p. 333). 
Dessa forma, compreende-se, então, que o ensino de todas as habilidades emergentes do livro didático é mediado pelos gêneros discursivos. Ainda, de acordo com as autoras, se o aluno entende a estrutura de um gênero, ele consegue utilizar essas informações na escrita de um texto, na sua compreensão, por exemplo.

Com relação ao ensino de análise linguística, as autoras assinalam que o estudo e a reflexão sobre a língua devem se orientar em condições reais de comunicação. Assim, o ensino de análise linguística, também permeada pelos gêneros discursivos de circulação social, pode fazer com que o aluno faça escolhas adequadas em relação à linguagem de cada gênero. Todavia, segundo Geraldi (2016), a análise linguística também auxilia o aluno não só a dominar o gênero discursivo, de acordo com a finalidade enunciativa da situação de interação verbal, e não só a escolher a linguagem em relação ao gênero. As atividades da análise linguística podem empoderar o aluno e, com isso, o ajudar no percurso de construção subjetiva e na busca pela autonomia.

Visto isso, neste trabalho, propomos analisar as atividades sugeridas pelas autoras, do ponto de vista da análise linguística e da teoria dos gêneros discursivos que, por sua vez, oportunizam ao aluno a sua constituição como sujeito. Apesar de o LD analisado trazer elementos teóricos da abordagem interacionista do processo de ensinoaprendizagem de português, muitas atividades de explorações textuais e dos elementos da língua fogem do escopo da teoria interacionista e voltam-se aos modos tradicionais de abstração e mecanização dos discursos, textos e elementos dos sistemas linguísticos explorados. A partir desta constatação, demonstramos quais atividades dão continuidade à tradição de usar textos como pretextos para o trabalho com taxonomia gramatical e de tipos textuais e quais abraçam os pressupostos dos gêneros discursivos e da análise linguística, eixos que preveem um aluno (sujeito) mais ativo e participativo nas aulas de língua portuguesa. Na seção seguinte, apresentamos alguns apontamentos sobre o ensino de gramática/análise linguística.

\subsection{0 ensino de gramática/análise linguística}

As práticas de análise linguística em sala de aula oportunizam ao aluno a reflexão sobre a língua, a compreensão do sistema linguístico e de usos da língua, tais atividades podem (re)significar o estudo da Gramática e, com isso, oportunizar aos alunos um maior domínio nos usos linguísticos em dadas situações interativas-enunciativas, especialmente nas atividades de leitura e escrita escolares. Todavia, conforme esclarece Geraldi (2016), as atividades de análise linguísticas são escassas, pois a escola ainda se concentra no estudo tradicional da gramática e há muitas confusões geradas pelo ensino de gramática como instrumento isolado de comunicação.

Para o autor, a aposta das atividades com análise linguística é que

[q]uando se propunha uma "prática de análise linguística", visava-se referir a um conjunto de atividades que tomam uma das características da linguagem como seu objeto: o fato de que ela pode remeter a si própria, ou seja, com a linguagem não só falamos sobre o mundo ou sobre nossa relação com ele e com os outros, mas também falamos sobre como falamos. (GERALDI, 2016, p. 16).

Nesta perspectiva, compreendemos que se faz necessário o ensino da língua, da reflexão sobre a língua e não só o ensino explícito de gramática, a partir do qual os alunos decoram nomenclaturas, classificações e outros aspectos linguísticos. A maioria dos LD de língua portuguesa opta por direcionar as atividades a partir da identificação das nomenclaturas da gramática tradicional por elas mesmas (SOUSA FILHO, 2017). Ainda sobre isso, Bezerra e Reinaldo (2013) esclarecem que, por meio da análise linguística, é oportunizado

aos alunos, por exemplo, no momento da leitura, compararem textos e refletirem sobre adequação linguística, sobre efeitos de sentido nos textos, procurando compreender e se apropriar das alternativas que a língua lhes oferece para sua comunicação (BEZERRA; REINALDO, 2012, p. 37).

Visto isso, ainda são mencionadas por Bezerra e Reinaldo (2013) a utilização de atividades (tipos de reflexão) epilinguística e metalinguística. De acordo com Franchi (2006), as atividades epilinguísticas se referem às atividades em que os alunos levantam hipóteses e fazem reflexões sobre o uso da língua.

Estudiosos, como Franchi (2006), Britto (1997), Bezerra e Reinaldo (2013), Brito e Sousa Filho (2015) e Araújo, Sousa Filho e Lima (2018), discutem o ensino de gramática/análise linguística nas aulas de língua portuguesa em diversas perspectivas e contextos de ensino e apostam que esse caminho metodológico traga mais êxito ao ensino de língua portuguesa.

Dessa forma, compreendemos que levar o aluno a pensar a língua por meio do ensino da análise linguística é de extrema importância, uma vez que oportunizará ao aprendiz refletir sobre a língua e fazer uso dessa reflexão em suas 
produções, sejam elas orais ou escritas. O que dificulta, no entanto, é o foco dado pelos livros didáticos às atividades que sugerem um "mascaramento" do ensino de análise linguística em exercícios tradicionais de gramática normativa, em que os alunos somente terão de nomear, classificar e fazer flexões de número, gênero e grau de determinados vocábulos, por exemplo.

Conforme mencionado anteriormente, o livro didático ainda é o principal recurso pedagógico em vários contextos de ensino e, assim, perspectivas como a análise linguística não são amplamente inseridas nas aulas, pois elas aparecem maquiadas ou distorcidas pela gramática normativa. Nesse sentido, o que vai ocorrer, então, em sala de aula, é a protelação desse tipo de atividade, o que levará o aluno a continuar sendo um mero repetidor de regras, termos e características de um ensino de gramática tradicional, ou seja, um usuário fidedigno da gramática normativa da língua portuguesa.

Tendo até aqui discutido os aspectos teóricos que abarcaram este estudo, na próxima seção, apresentamos, de maneira suscinta, a metodologia adotada para esta investigação e de como se dará a análise dos dados oriundos das atividades que foram propostas pelas autoras do livro didático.

\section{METODOLOGIA}

Para a realização deste estudo, adotamos uma abordagem de cunho qualitativa do tipo descritiva que, segundo Prodanov e Freitas (2013), se refere a um tipo de investigação em que o pesquisador registra e descreve os fatos observados, com enfoque na pesquisa documental e bibliográfica (GOLDEN-BERG, 1999; GIL, 2010; SILVA; MENEZES, 2005), uma vez que utilizamos como instrumento de coleta e análise de dados um livro didático e as atividades que abordam o uso dos gêneros discursivos dispostos nele.

Nessa vertente, segundo Gil (2008), a pesquisa documental "baseia-se em materiais que não receberam ainda um tratamento analítico ou que podem ser reelaborados de acordo com os objetivos da pesquisa" (GIL, 2008, p. 55).

Visto isso, para nossas análises neste trabalho, selecionamos no LD as atividades das seções que "orientam o uso do registro de linguagem adequada ao gênero e à situação (formal, informal)". (BORGATTO; BERTIN; MARCHEZI, 2015, p. 3). Coletamos 07 atividades que abordam gêneros discursivos distintos e, assim, procuramos descrever e analisar tais atividades. Sendo assim, na escolha do nosso objeto de pesquisa, buscamos interpretar no conjunto composto por 07 atividades de língua (leitura, escrita, fala e escuta) como as informações contidas nele podem direcionar o trabalho do professor em sala de aula. Servem como eixo para nossas análises as noções de gênero do discurso e de análise linguística, considerando estudos anteriores, como os de Reinaldo e Bezerra (2013), Brito e Sousa Filho (2015), entre outros, que tratam dessa temática.

\section{DISCUSSÃO DOS DADOS}

Conforme mencionado anteriormente, o livro didático Projeto Teláris - Língua Portuguesa, do $6^{\circ}$ ano do Ensino Fundamental, tem a perspectiva do ensino das habilidades da língua portuguesa por meio dos gêneros discursivos. Nesse sentido, as análises das atividades selecionadas serão também direcionadas a essas teorias, relacionando-as com as proposições das autoras nos exercícios dispostos no livro.

Para a análise de dados, dividimos as atividades em três categorias. A primeira delas discutirá atividades que são intrinsecamente gramaticais e, a segunda, por sua vez, apresentará a análise de atividades em que o foco recai na gramática, mas que ainda proporciona o ensino de outras habilidades da língua como, por exemplo, a interpretação de textos.

Por fim, a terceira categoria - que encerra a análise dos dados - apresenta atividades sem o "ranço" do ensino da gramatical tradicional, as quais podem ocasionar momentos de reflexão do aluno por meio de discussões, interpretações textuais, produções, entre outros, isto é, podem ser classificadas como atividades de análise linguística. 


\subsection{Atividades com foco estritamente gramatical}

Na figura a seguir, apresentamos o primeiro exemplo das atividades dispostas no livro didático. Essa atividade foi classificada por nós como uma atividade que traz o foco totalmente no ensino de gramática.

\section{Dragão}

O dragão é um dos monstros mais conhecidos das histórias. Geralmente é um lagarto imenso, com asas e garras, que tem o poder de lançar fogo de sua boca ou narinas. Nas histórias do Oriente, os dragões costumam ser antigos, sábios e do bem, dignos de adoração das pessoas. Já em contos ocidentais, eles são considerados seres malignos, demoniacos e destruidores.

Consta ainda que os dragões adoram riquezas e juntam nas cavernas objetos brilhantes roubados, que protegem deitando-se sobre eles para que ninguém os roube. $O$ ouro e as joias carregam uma maldição: quem se apossar deles será vitima da ambição pelo ouro e jamais será feliz.

RIOS, Rosana. O livro dos sustos: o que fazer nas situações horripilantes da vida. São Paulo: Atica, 2006. p. 47.

Como tudo o que existe tem nome, localize no texto os nomes indicados e escreva-os no caderno.
a) Nome de sentimento ou ação.
d) Nome de seres imaginários.
b) Nome de lugar.
e) Nome de ser vivo, animal.
c) Nome de partes do corpo.
f) Nome de objetos.

Figura 1. Atividade 1

Fonte: BORGATTO; BERTIN; MARCHEZI, 2015, p. 97.

Conforme notamos, o texto Dragão foi usado unicamente para o ensino de gramática. Assim, o aluno terá somente que passar os olhos no texto a fim de descobrir nomes como, por exemplo, de sentimentos, de seres, de objetos, entre outros, corroborando, assim, aos apontamentos de Franchi (2006), ao sugerir que "a gramática não é relacionada a um melhor entendimento dos processos de produção e compreensão de textos" (FRANCHI, 2006, p. 34). Desta forma, neste exemplo de atividade, o texto é usado como pretexto para o ensino de nomes ou substantivos, ou seja, o texto serve de pretexto para a identificação de palavras pertencentes à classe dos nomes.

Na próxima atividade, disposta a seguir, notamos, novamente, o uso dos gêneros discursivos, no caso a charge, a qual, por sua vez, possui caraterísticas críticas e temporais e que, assim, poderia promover discursos calorosos entre os aprendizes, mas ela é usada no LD com vistas a atender um mero exercício gramatiqueiro.
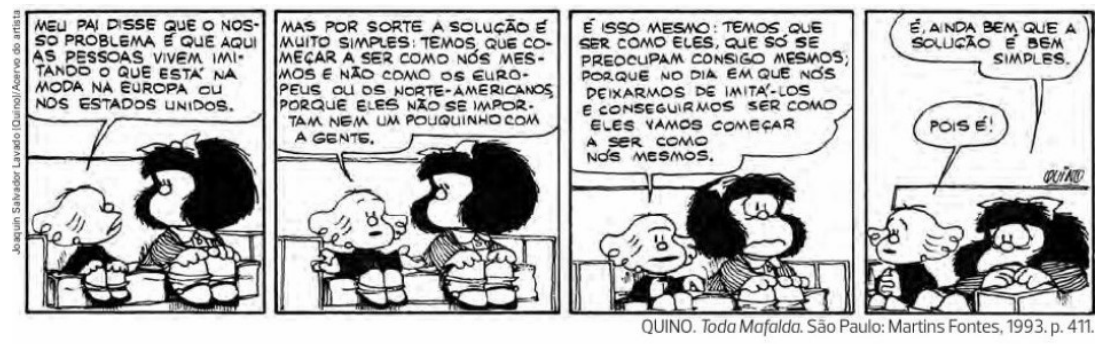

\footnotetext{
a) No segundo quadrinho, a personagem diz:

[...] eles não se importam nem um pouquinho com a gente.

- Responda no caderno: na linguagem do dia a dia a expressão "a gente" se refere a que pessoa do discurso?

- No caderno, reescreva a frase substituindo a expressão "a gente" por um pronome equivalente.

b) No terceiro quadrinho, a que palavra se refere o pronome consigo?
}

Figura 2. Atividade 2

Fonte: BORGATTO; BERTIN; MARCHEZI, 2015, p. 171. 
Como se nota na charge, o uso do texto foi focado no ensino de gramática. No entanto, poderia ser utilizado para o ensino de outros aspectos da língua como, por exemplo, a produção de textos, conforme sugere Geraldi (1997 e 2016). Coadunando com os apontamentos do autor de que, por meio da escrita baseada na charge o aluno poderia, mediante o seu discurso, "remeter a uma relação intersubjetiva constituída no próprio processo de enunciação marcada pela temporalidade e suas dimensões". (GERALDI, 1997, p. 135). Ainda, nesse sentido, ao se trabalhar o processo de produção textual, pode-se partir do próprio texto do aluno para o ensino da gramática que, por sua vez, conforme nos esclarece Reinaldo e Bezerra (2013), pode auxiliar o aluno neste processo.

Desse modo, o aluno poderia se expressar, visando a sua constituição como sujeito, por meio da formação do seu discurso, ao utilizar os gêneros discursivos, ao passo que estes se fazem presentes em todas as esferas das atividades humanas (BAKHTIN, 2011; FARACO, 2009). Ainda, em relação a este aspecto, encontramos esclarecimentos em Reinaldo e Bezerra (2013), que sugerem que devemos partir "do gênero textual para chegarmos às unidades linguísticas, considerando a língua como ação entre seus usuários (interação)" (REINALDO E BEZERRA, 2013, p. 64).

Finalizamos a seção, citando outro exemplo de atividade que se vale do texto como pretexto para ensinar normas gramaticais. Vejamos.
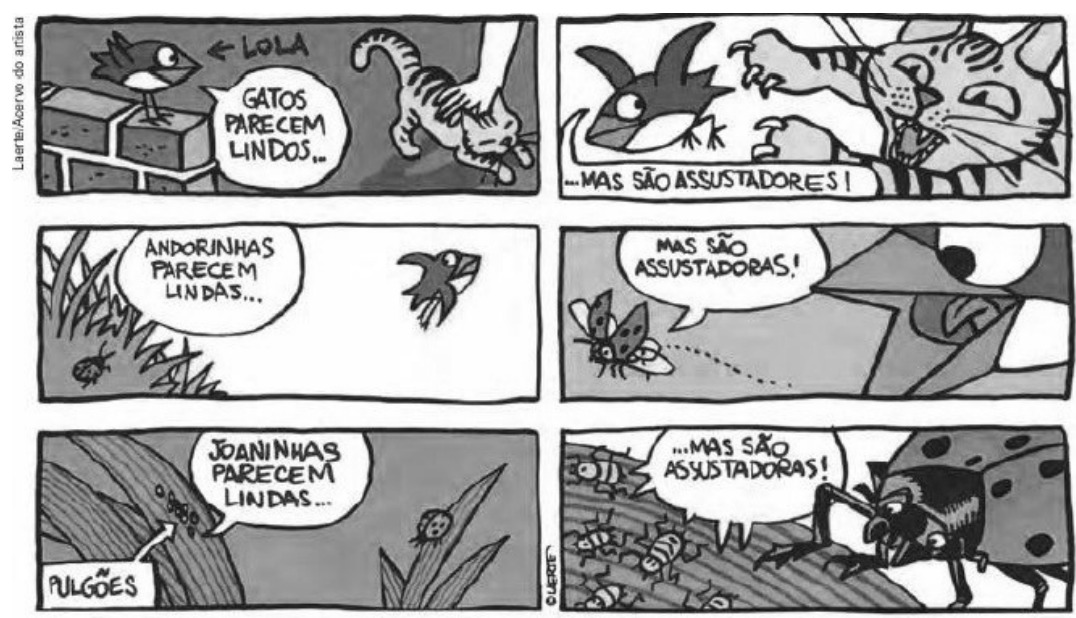

LAERTE. Lola, a Andorinha. Folho de S.Paulo. São Paulo, 7 maio 2011. Folhinha, p. 8.

a) Reescreva no caderno as frases a seguir completando as lacunas adequadamente.

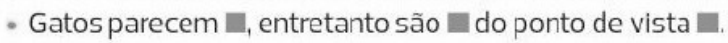

- Andorinhas parecem $\mathbf{n}$, entretanto são $\mathbf{E}$ do ponto de vista $\mathbf{E}$.

- Joaninhas parecem $\mathbf{n}$, entretanto são 1 do ponto de vista $\mathbf{E}$.

b) Pense em algo que de determinado ponto de vista parece lindo, mas que, de seu ponto de vista, é assustador. Em seu caderno, copie a estrutura da frase a seguir comparando esses pontos de vista.

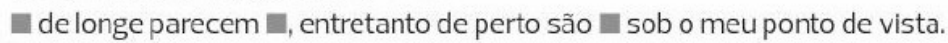

Figura 3. Atividade 3

Fonte: BORGATTO; BERTIN; MARCHEZI, 2015, p. 117

Neste exemplo de atividade, o que mais chama a atenção é a condução da atividade que o aluno tem de realizar. Como podemos observar, os estudantes têm somente que completar as frases (na verdade, copiar) dos quadrinhos numa maneira de repetição de termos (BLOOMFIELD, 1933; SKINNER, 1957). A atividade (a) é um mero exercício de repetição de estrutura, sem nenhum propósito de uso significativo da língua, com exceção da inclusão das expressões entretanto e do ponto de vista nas estruturas que os alunos têm de construir.

Por outo lado, o exercício (b) tende a fazer com que o aluno pense em algo, semelhante ao que foi repetido para completar a frase, porém, ainda se constitui também como um exercício de repetição de estruturas prontas, sem ao menos dar oportunidades para o aluno pensar ou refletir sobre as várias possiblidades de fazer afirmações, da variação interna e externa da língua.

Nesta seção, discorremos sobre o uso do texto como pretexto para o ensino de gramática. Apesar de o livro usar os termos gêneros discursivos, as atividades demonstram pertencer a outra vertente teórica. A seguir, 
continuamos esta discussão, mas, no entanto, apresentamos atividades que permitem o ensino de outras habilidades da língua portuguesa.

\subsection{Atividades com foco gramatical, mas que sugerem novas perspectivas de ensino}

O ensino de língua portuguesa direcionado pelo uso de gêneros discursivos pode propiciar ao aluno o conhecimento de aspectos linguísticos como o ensino da gramática, mas, também, da interpretação e da produção textual, conforme podemos notar na figura a seguir.

Inutilidades

José Paulo Paes

Ninguém coça as costas da cadeira.

Ninguém chupa a manga da camisa.

O piano jamais abana a cauda.

Tem asa, porém não voa, a xicara.

Desafio! Em dupla.

a) Copiem em uma folha de papel as palavras em destaque no poema.

De que serve o pé da mesa se não anda?

b) Escrevam, no menor tempo possivel, na frente de cada palavra, o sentido próprio dela, que é diferente do sentido dado pelo poeta.

E a boca da calça se não fala nunca?

Nem sempre o botão está na sua casa.

O dente de alho não morde coisa alguma.

c) Ao terminar, a dupla deve erguer a folha de papel preenchida.

Ah! Se trotassem os cavalos do motor...

d) Vencerá a brincadeira a equipe que terminar primeiro e acertar o significado de todas as palavras ou do maior número delas.

Ah! Se fosse de circo o macaco do carro

Então a menina dos olhos comeria

até bolo esportivo e bala de revólver.

PAES, José Paulo. E Eisso ali. São Paulo:

Salamandra, 1993

Figura 4. Atividade 4

Fonte: BORGATTO; BERTIN; MARCHEZI, 2015, p. 289.

Nessa atividade, o foco recai na identificação dos substantivos e suas significações conotativas e denotativas. Podemos visualizar que, além do ensino de aspectos linguísticos como sentido figurado e sentido literal, o exercício ainda dá a possibilidade de fazer com que os alunos interajam entre si. Nesse sentido, podem começar juntos a ter domínio do gênero, conforme esclarece Faraco (2009), por meio da interação com os outros colegas. Ainda, em relação a esta atividade, a função da análise linguística aqui coaduna com "a linguagem em funcionamento entre os sujeitos nas diversas situações de interação" (ARAÚJO; SOUSA FILHO; LIMA, 2018, p.277) entre eles.

A produção de sentidos por meio da interpretação textual e utilização dos gêneros discursivos para atividades de análise linguística pode ser percebida na figura a seguir, que sugere, além dos aspectos linguísticos vistos por meio da variedade linguística, a discussão entre os alunos sobre a linguagem.

Cuitelinho

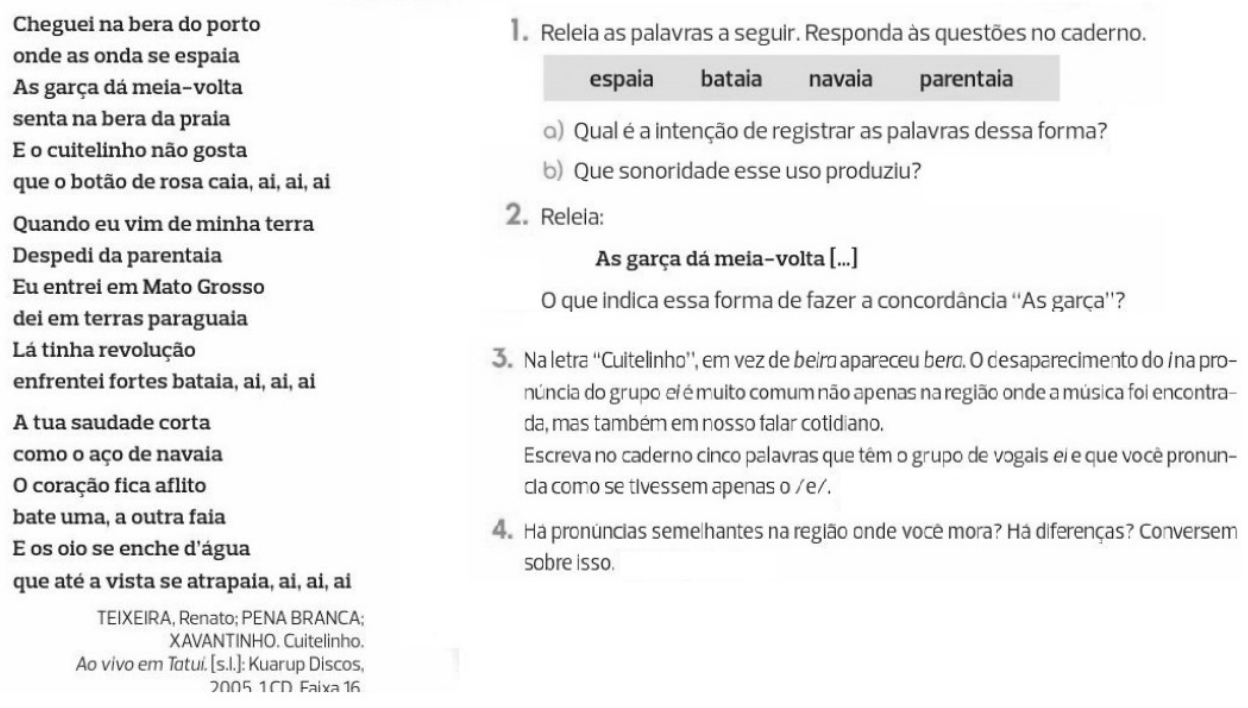

Figura 5. Atividade 5

Fonte: BORGATTO; BERTIN; MARCHEZI, 2015, p. 36-37. 
Nesta atividade, como dito anteriormente, os alunos terão a oportunidade de conhecer a variedade linguística e de usar o texto para discutirem sobre possibilidades de variantes linguísticas em sua região. Dessa forma, poderão refletir e produzir enunciados por meio de práticas e uso significativo da linguagem, conforme sugerem Bakhtin (2009) e Faraco (2009), por meio da interação discursiva entre os alunos.

Por fim, na terceira seção desta análise, apresentamos atividades trazidas pelo livro didático que fogem do aspecto puramente gramatical.

\subsection{Atividades sem foco puramente gramatical}

$\mathrm{Na}$ atividade, disposta na figura a seguir, podemos identificar que no livro didático também há exercícios com o uso de gêneros discursivos, os quais, por sua vez, fogem do aspecto puramente gramatical. Essas atividades são muito diferentes das apresentadas nas seções anteriores, que são, como dissemos, demasiadamente gramatiqueiras, no sentido de explorarem a gramática por ela mesma e perpetuar a prática de repetição das nomenclaturas da gramática prescritiva/normativa tradicional.

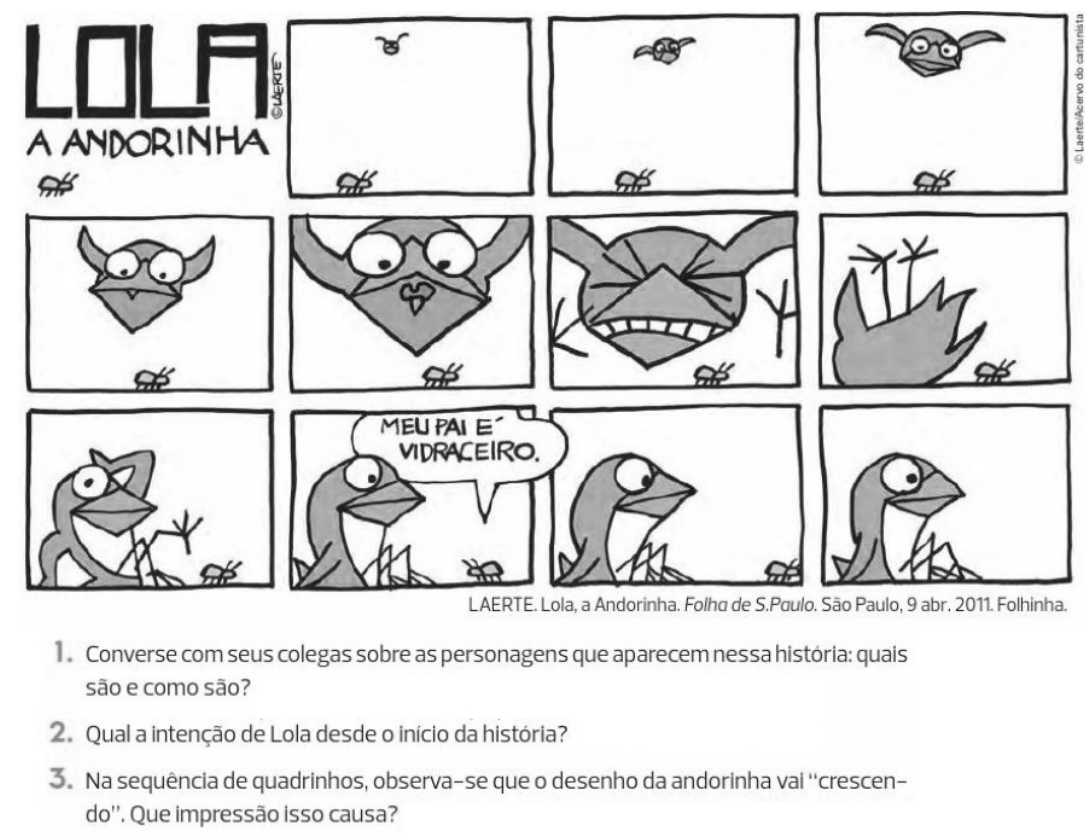

Figura 6. Atividade 6

Fonte: BORGATTO; BERTIN; MARCHEZI, 2015, p. 28.

Por meio das atividades de 1 a 3, percebe-se que o uso da charge oportuniza a interação entre os alunos e, assim, a fazer uso significativo da língua por meio da exposição de ideias e da sua compreensão sobre o que acabaram de ler, permitem que a interação entre eles possa ocorrer e, a partir dela, proporcionam reflexões sobre a língua viva e sobre a vida (BAKHTIN, 2011; FARACO, 2009). Os exercícios não são apenas de identificação, mas provocam reflexão coletiva sobre o gênero discursivo e sobre a língua/gem.

A seguir, apresentamos uma atividade que aborda aspectos culturais de uma sociedade, ao fazer relações entre as formas de empregar a língua entre as diversas faixas etárias. 


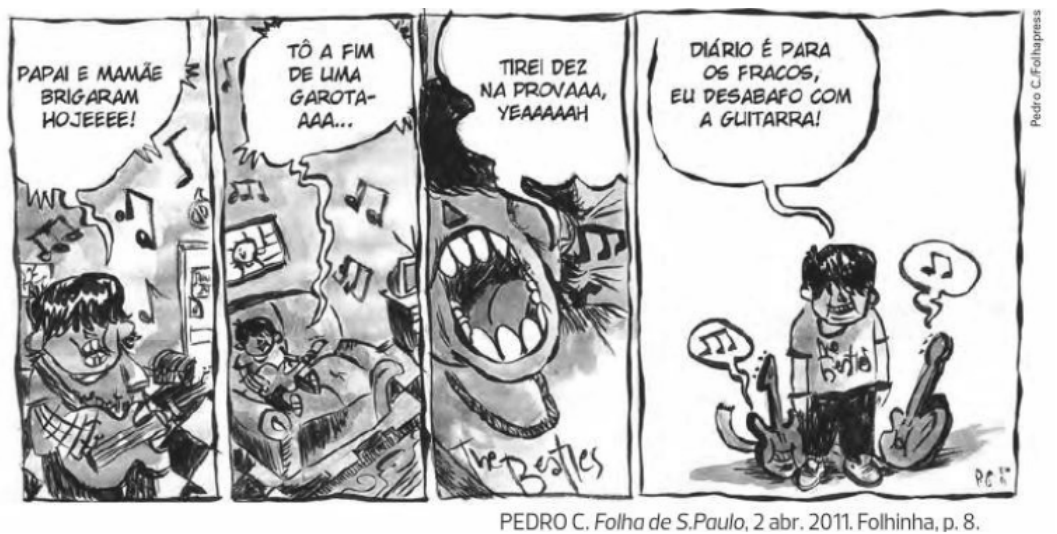

Algumas formas de empregar a lingua podem revelar a faixa etária de quem fala.

a) Na tira acima, que expressão indica que a personagem é jovem?

b) Se a frase fosse dita por uma pessoa bem mais velha, como ela provavermente falaria?

3. Converse com seus colegas e pensem que palavras ou expressões são usadas por vocês e que não são empregadas, por exemplo, por pessoas mais velhas. Façam uma lista e verifiquem as várias formas de expressão em uma mesma lingua.

4. Faça um levantamento entre os colegas da classe para verificar se há alunos vindos de regiões diferentes. Observe as caracteristicas de cada um na forma de empregar a língua: a pronúncia, o uso de certas palavras ou expressões.

É importante respeitar a forma de falar de cada um, pois todas as formas são válidas.

Figura 7. Atividade 7

Fonte: BORGATTO; BERTIN; MARCHEZI, 2015, p. 38

Com o uso dessa atividade, diferentemente das atividades gramatiqueiras que o livro apresenta, o aluno pode se expressar por meio da linguagem e conversar com os colegas sobre como empregam a língua, sobre como as pessoas em seu contexto social empregam a língua, ou seja, pode haver entre eles atividades linguísticas, epilinguísticas e metalinguísticas. Podem compreender como o uso social da língua constitui as relações intersubjetivas na vida cotidiana (Bakhtin, 2009).

Dessa forma, esse tipo de interação, que pode e deve ocorrer entre os alunos em sala de aula, corrobora com os apontamentos de Bakhtin (2009) de que a língua não é um sistema abstrato de regras e evolui historicamente, num processo ininterrupto que se dá por meio da interação verbal dos indivíduos.

Finalizando nossas discussões acerca das atividades propostas pelo livro didático, apresentamos nossas considerações finais.

\section{CONSIDERAÇÕES FINAIS}

Procuramos neste artigo evidenciar o ensino de gramática que "mascara" a perspectiva do ensino de análise linguística. Ainda, tivemos como objetivo apresentar a variedade de gêneros discursivos que a aula de língua portuguesa oportuniza para que os alunos tenham contato e, por que não, o domínio desses gêneros.

As razões para que o professor, sobretudo o da escola pública, se fixe no LD como instrumento de trabalho (às vezes, o único) são diversas e de variadas ordens, e vão desde a formação inicial até a sobrecarga de trabalho, o acesso escasso a outros materiais, a baixa remuneração e tantas intempéries que podem impedi-lo de construir uma visão interacionista do processo de ensino-aprendizagem. Assim, o LD figura para muitos professores como o único material disponível para o trabalho e, desafortunadamente, faltam-lhe condições para ressignificar os LD e, consequentemente, as aulas de língua portuguesa (BEZEIRRA; REINALDO, 2013). Sendo assim, ao seguir o LD, sem uma problematização acerca desse instrumento pedagógico e sem a busca por LD ressignificados, o que resta em sala de aula nas atividades de língua portuguesa é um engessamento de práticas docentes que direcionam o ensino para a gramática tradicional explícita. Dessa forma, o aluno passa a ser um mero replicador de normas e, conforme a premissa da análise linguística, não se torna um indivíduo que pensa, reflete e usa a língua de forma significativa, pois 
sem a reflexão sobre os usos da língua, das situações enunciativas e dos momentos de interações, o aluno será apenas repetidor de normas prontas e acabadas.

As iniciativas para que os processos de ensino-aprendizagem de línguas sejam modificadas existem, especialmente as provindas das esferas governamentais. Os Parâmetros Curriculares Nacionais (PCN) (BRASIL, 1998) deram abertura para que o ensino adotasse uma perspectiva interacionista da linguagem; os gêneros discursivos conduzissem as atividades relacionadas à habilidades e competências da disciplina língua portuguesa; e apresentaram o eixo pedagógico Análise Linguística como o carro chefe para tratar das ações que fazemos com a linguagem, das que fazemos sobre a linguagem e da ações da linguagem.

Duas décadas do lançamento dos PCNs se passaram e, de acordo com Sousa Filho e Moura (2020), as atividades de análise linguística não alcançaram o chão da escola. A oportunidade para reverter essa situação é aventada pelo lançamento da Base Nacional Comum Curricular (BNCC) (BRASIL, 2018), o que não ocorreu, segundo a visão de Sousa Filho (no prelo), para quem, a ausência da categoria Atividades Epilinguísticas no eixo Análise Linguística delineado pela BNCC nos auxilia na constatação de que o documento abandona o pilar do referido eixo, o qual, ao se tornar limitado/deficitário, não conseguirá ser uma alternativa ao ensino das nomenclaturas gramaticais ou das taxonomias de gêneros discursivos.

Assim, os desafios para o professor mudar de postura e ter um trabalho textual e de análise linguística guiados pela perspectiva interacionista aparecem nos LD, mas vão além deles. Nesse sentido, para que as mudanças aconteçam, elas precisam fazer parte de um plano mais de ação da sociedade escolar e da sociedade civil. No que se refere ao trabalho com o LD e, portanto, à uma mudança pontual, espera-se que o professor redimensione as atividades linguísticas em suas aulas e utilize os gêneros discursivos e a análise linguística a favor do ensino de língua portuguesa. Assim, ele poderá levar seu aluno a pensar e a usar a língua em suas mais variadas esferas das atividades de realização, por meio de interações comunicativas.

\section{REFERÊNCIAS}

ARAUJO, M. D. M.; FILHO, S. M. S.; LIMA, L M. (2018). Espelho, espelho, meu: concepções de linguagem e ensino de gramática/análise linguística no ensino médio. PERcurso Linguísticos, v. 8, n. 18, p. 272-291.

BAKHTIN, M. (VOLOCHÍNOV). (2009). Marxismo e Filosofia da Linguagem. São Paulo: Hucitec.

BAKHTIN, M. (VOLOCHÍNOV). (2011). Os gêneros do discurso. In: Fontes, p. 261-269.

BEZERRA, M. A.; REINALDO, M. A. (2013). Análise Linguística: afinal, a que se refere? São Paulo: Cortez.

BLOOMFIELD, L. (1993). Language. New York: Holt, Rinehart and Winston.

BRASIL. (2018). Base Nacional Curricular Comum: Educação é a base. Brasília: MEC/SEB, 2018.

BRASIL. (1998). Parâmetros Curriculares Nacionais. MEC/SEB.

BRITO, J. A. G.; SOUSA FILHO, S. M. (2015). O rap em sala de aula: uma proposta pautada em Bakhtin e em análise linguística. In: SOUSA FILHO, S. M. e ARAUJO, L. K. (org.) Gêneros discursivos e análise linguística no ensino de línguas. Campinas: Pontes Editores, p. $99-112$.

BRITTO, L. P. L. (1997). A sombra do caos: ensino de língua x tradição gramatical. Tese de Doutorado em Linguística. Instituto de Estudo da Linguagem, Universidade Estadual de Campinas, Campinas.

BORGATtO, A. M. T.; BerTiN, T. C. H.; MARCHEZI, V. L. C. (2015). Projeto Teláris - Língua Portuguesa $6^{\circ}$ ano. São Paulo: Ática.

CERUTTI-RIZZATTI, M. E. (2010). Ensino de língua portuguesa e inquietações teórico-metodológicas: os gêneros discursivos na aula de português e a aula (de português) como gênero discursivo. ALFA: Revisa Linguística, v. 1, n. 56, p. 249-269. Disponível em: < http://seer.fclar.unesp.br/alfa/article/ view/4968/0>. Acessado dia: 20 mar. 2020. 
CHOMSKY, N. (1957). Syntactic structures. Mouton: The Hague.

CORACINI, M. J. (1999). Interpretação, autoria e legitimação do livro didático. Campinas: Pontes.

FARACO, C. A. (2009). Linguagem e diálogo: as ideias linguísticas do Círculo de Bakhtin. São Paulo: Parábola Editorial.

FRANCHI, C. (2006). Mas o que é mesmo "gramática"? In: POSSENTI, S. (Org.). Mas o que é mesmo "gramática"? São Paulo: Parábola, p. 11-23.

GERALDI, J. W. (1997). Portos de passagem. 4. ed. São Paulo: Martins Fontes.

GERALDI, J. W. (2015). O ensino de língua portuguesa e a Base Nacional Comum Curricular. Revista Retratos da Escola, Brasília, v. 9, n. 17, p. 381-396, jul./dez. Disponível em: < retratosdaescola.emnuvens.com.br/rde/article/download/587/661>. Acessado em: 5 nov. 2019.

GERALDI, J. W. (2016). Atividades epilinguísticas no ensino da língua materna. Atas do SIELP/V FIAL: Simpósio Internacional de Ensino de Língua Portuguesa, Fórum Ibero-Americano de Literacias, 2016, p. 12-22. Disponível em: < http://repositorium.sdum. uminho.pt/handle/1822/44992>. Acessado em: 5 nov. 2019.

GIL, A. C. (2008). Métodos e técnicas de pesquisa social. 6. ed. São Paulo: Atlas.

GIL, A. C. (2010). Como elaborar projetos de pesquisa. 5. ed. São Paulo: Atlas.

GOLDEN-BERG, M. (1999). A Arte de Pesquisar. Rio de Janeiro: Record.

LAJOLO, M. (1996). Livro didático: um (quase) manual de usuário. Em aberto, Brasília, v. 16, n. 69, p. 3-9, jan/mar.

MARCHENKOVA, L. (2005). Language, culture and self. In: HALL, J. K.; VITANOVA, G.; MARCHENKOVA, L. (Ed.). Dialogue with Bakbtin on second and foreign language learning: new perspectives. New Jersey: Lawrence Erlbaum Associates, p. $171-188$.

MACHADO, I. (2013). Gêneros discursivos. In: BRAIT, B. (Org.). Bakhtin: conceitos chave. São Paulo: Editora Contexto, p. $151-166$

MARCUSCHI, L. A. (2008). Produção textual, análise de gêneros e compreensão. São Paulo: Parábola editorial.

MELLO, G. N. (1999). O livro didático no sistema de ensino público do Brasil. São Paulo: Ebrap.

PIRES, V. L.; SOBRAL, A. (2013). Implicações do estatuto ontológico do sujeito na teoria discursiva do Círculo Bakhtin, Medvedev, Voloshinov. Bakbtiniana, São Paulo, v. 8, n. 1, p. 205-219.

PRODANOV, C. C.; FREITAS, E. C. de. (2013). Metodologia do trabalbo Científico: Métodos e Técnicas da Pesquisa e do Trabalho Acadêmico. 2. ed. Novo Hamburgo: Feevale.

RABELO, Z. da S. (2015). Livros didáticos de língua portuguesa: uma análise da seção projetos. Mestrado em Letras. Centro de Artes e Comunicação, Universidade Federal de Pernambuco, Recife.

SILVA, E. L.; MENEZES, E. M. (2005). Metodologia da Pesquisa e Elaboração de Dissertação. Florianópolis: Laboratório de Ensino a Distância da UFS.

SOUSA FILHO, S. M. (2009). Relações entre Literatura, Linguística e Ensino de Português. In: CAMARGO, F. P. e FRANCA, V. G. (Org.). Estudos sobre Literatura e Linguística - Pesquisa e Ensino. 1ed.São Carlos: Claraluz, v. 1, p. 149-162.

SOUSA FILHO, S. M. (2017). A prática de análise linguística na aula de português. In: ASSIS, E. F. (Org.). Caminhos para a educação linguística. 1 ed. Campinas: Pontes Editora, v. 1, p. 41-56.

SOUSA FILHO, S. M. A ausência da categoria Atividade Epilinguística no eixo pedagógico Prática de Análise Linguística na BNCC. (no prelo). 
SOUSA FILHO, S. M.; MOURA, L. M. (2020). Propostas da Base Nacional Comum Curricular (BNCC) e de livros didáticos para o ensino da variação linguística no ensino fundamental anos finais. JNT - Facit Business and Technology Journal, vol. 2, p. 70-91.

SKINNER, B. F. Verbal bebavior. (1957). New York: Appleton Century Crofts.

Recebido: 21/5/2020

Aceito: 1/2/2021

Publicado: 11/3/2021 